\title{
Effect of sandwich bone augmentation using hydroxyapatite and demineralized freeze- dried bone on infrabony pocket treatment
}

\author{
Eka Pramudita Ramadhany*, Al Sri Koes Soesilowati**, Sri Pramestri Lastianny**凶 \\ *School of Dentistry, Faculty of Medicine, Udayana University, Bali, Indonesia \\ Periodontics Specialty Program, Faculty of Dentistry, Universitas Gadjah Mada, Yogyakarta, Indonesia \\ **Departement of Periodontics, Faculty of Dentistry, Universitas Gadjah Mada, Yogyakarta, Indonesia \\ **JI Denta No 1, Sekip Utara, Yogyakarta, Indonesia; $₫$ correspondence: sri.pramestri@ugm.ac.id
}

Submitted: $24^{\text {th }}$ July 2018; Revised: 27 th February 2019; Accepted: $15^{\text {th }}$ April 2019

\begin{abstract}
Periodontitis is periodontal inflammation in response to plaque bacterial antigens, causing damage to periodontal ligament and alveolar bone resorption. Bone graft material combination i.e. demineralized freeze-dried bone allograft (DFDBA) and hydroxyapatite (HA) using sandwich bone augmentation (SBA) method will support each other and will be beneficial to be used as a scaffold. The body takes long time to resorb HA so this could complement DFDBA which is more easily dissolved. This study aimed to reveal the effect of bone graft addition using SBA method on the treatment of infrabony pocket with open flap debridement in terms of probing depth, relative attachment loss, alveolar bone height, and density. This study was carried out to 20 infrabony pockets, where 10 of them were treated using open flap debridement with HA addition, while the other 10 groups were treated using open flap debridement with DFDBA and HA using SBA method. Probing depth and relative attachment loss were measured on days 0,30 and 90 . Bone height and density were measured using cone-beam computed tomography (images on day 0 and 90). The study showed that probing depth reduction on SBA group was greater than HA group. There were significant differences in probing depth and relative attachment loss examinations. However, bone height and bone density reduction did not show any significant difference. The conclusion from this study is open flap debridement using SBA method yields better regeneration in terms of probing depth and relative attachment loss than open flap debridement with HA addition. There is no difference in bone height and bone density between the two groups.
\end{abstract}

Keywords: bone graft; infrabony pocket; sandwich bone augmentation

\section{INTRODUCTION}

Periodontitis is a destructive and irreversible inflammatory disease in periodontal tissues affecting gingival, periodontal ligament, and alveolar bone. ${ }^{1}$ This disease is characterized by supra and sub-gingival plaque and calculus accumulation, gingival inflammation, apical migration of junctional epithelium, clinical attachment loss, loss of alveolar bone, and sometimes suppuration. Bone defects in injured periodontal tissues as an effect of inflammatory response or surgical procedure will heal through regeneration or repair processes. Periodontal regeneration can be done by regenerative periodontal therapy with bone graft treatment using various bone graft materials according to their functions. The functions of bone graft are osteoconduction, osteoinduction, and osteogenesis to induce bone formation and periodontal regeneration through a new attachment process. In bone remodeling, osteoblasts require scaffold that supports cell attachment, osteoblast proliferation in defects, and clot stabilization, as well as prevents damage to tissues in the early stages of regeneration. ${ }^{2}$

Infrabony pocket requires more complex treatment. Guide tissue regeneration technique, i.e. periodontal treatment using membrane as barrier to prevent apical migration of cells in the epithelial tissues, is among therapy of infrabony pocket. The membrane used can be either resorbable or nonresorbable. ${ }^{3}$ Currently, clinician combined guide tissue regeneration and bone graft materials to treat bone damage or defects. ${ }^{4}$ 
Recent research develops a guided bone regeneration or bone augmentation method which combines two or more types of bone grafts called sandwich bone augmentation (SBA). This method maximizes bone formation by utilizing the positive properties of various types of grafts. The main component of SBA is demineralized freeze-dried bone allograft (DFDBA). This type of bone graft contains collagen which is the most important component of bone tissues. Besides, DFDBA releases bone morphogenic protein which promotes bone formation in surgical area. Contact between DFDBA and bone will create an ideal environment for the migration and proliferation of osteogenic cells. The outer layer of bone graft is HA which functions as a scaffold or space occupier because it has osteoconductive properties. The properties support new bone formation by maintaining and or protecting important gaps in bone augmentation procedures. ${ }^{5}$

Guided bone regeneration or bone augmentation is developed from guided tissue regeneration in periodontal treatment which aims to prevent non-osteogenic cells from entering bone defect. Regeneration is the final goal of both guided tissue regeneration and guided bone regeneration; the difference is that guided tissue regeneration is done to the supporting tissues of teeth while guided bone regeneration is done to edentulous area followed by dental implant, ${ }^{6}$ but the results of guided bone regeneration are highly varied due to depend on the properties of bone graft materials. ${ }^{4}$ This study aimed to determine the effect of SBA method on infrabony pocket treatment with open flap debridement.

The healing process of bone passes through the same phase as general wound healing. The inflammation and proliferation phase lasts about 6-8 weeks, the remodeling phase lasts for several months or years. ${ }^{7}$ Healing bone destruction occurred after one month of bone graft planting and after 3 months was apparent on radiographic examination. The process of mineralization and bone density will increase significantly in the six months after bone graft. $^{8}$

\section{MATERIALS AND METHODS}

This was a quasi-experimental research. The materials used are periodontal probe type UNC 15 (PB UNC 15, Osung MND Co. Ltd., Republic of Korea), collagen membrane (CollaTape, Zimmer Dental Inc., USA), DFDBA bone graft (National Nuclear Energy Agency, Indonesia), HA bone graft (Osbone, Curasan Inc., USA). This research has been approved by research ethics committee of Faculty of Dentistry, Universitas Gadjah Mada number 001235/KKEP/FKG-UGM/EC/2017. Participant of this study received detail of this study and signed informed consent. Ten subjects were selected in accordance with criteria: single root tooth, pocket depth more than $5 \mathrm{~mm}$, and no sistemic disease. Clinical examination consisted of measurements of plaque index and initial phase therapy consisting of dental health education, scaling root planing, occlusion adjustment, and splinting if there were luxation teeth with mobility greater than 1 degree.

The measurement of probing depth and relative attachment loss was performed on the treated teeth. Cone-beam computed tomography imaging was also performed as initial data, followed by the measurement of alveolar bone height, i.e. the distance between cemento- enamel junctions to the base of the most apical part of defect from the vertical direction of the bone. The periodontal flap surgical procedure started with local anesthesia lidocaine HCL $2 \%$ administration using infiltration technique after the surgical area was disinfected. Vertical and sulcular full thickness flap incisions were performed. The flap was elevated and debridement was performed by scaling, root planing, and curettage. Tetracycline $\mathrm{HCl} 75 \mathrm{mg} / \mathrm{ml}$ solution was applied to the hard tissue using sterile cotton pellets for 3 minutes. The cotton pellet was replaced every 30 seconds and rinsed using distilled water.

Bone graft materials were applied according to the treatment groups after open flap debridement. In SBA group, DFDBA was applied as first layer and HA was covered the DFDBA layer entirely. In the other group, HA was applied on the entire bone defect. On both groups, collagen membrane application and fixation were performed before returning and 
Majalah Kedokteran Gigi Indonesia. December 2019; 5(3): 114 - 119

ISSN 2460-0164 (print)

ISSN 2442-2576 (online)

suturing the flap. The treatment area was covered with periodontal dressing. The patients were given antibiotics, analgesics, and antiinflamatory drugs. Prior to discharged, patients were given instruction and explanation on how to maintain oral health after surgery. The control was done 7 days later to remove the periodontal dressing. Oral hygiene and wound healing evaluation was scheduled once a week for 4 weeks after periodontal flap surgery.

Clinical parameter data, including probing depth and relative attachment loss after the surgical procedure in each group were collected on the baseline day when treatment was initiated, after 30 days, and 90 days. Images were taken on the baseline and day 90 after the flap surgery to examine changes in alveolar bone height and density.

\section{RESULTS}

The data collected in this study were the results of clinical parameter measurements, such as probing depth and relative attachment loss. Data on alveolar bone height and density were derived from radiological examination. All evaluation were performed in the two groups of patients suffering from chronic periodontitis with infrabony bone damage. The regenerative periodontal treatment using open flap debridement combined with HA or SBA.

Table 1 showed the highest mean of probing depth was on SBA group on day $0(8.70 \pm 2.83)$ $\mathrm{mm}$. The lowest mean of probing depth was showed by SBA group on day $90(0.60 \pm 0.51) \mathrm{mm}$. The initial values of probing depth of $\mathrm{HA}$ and SBA group were different, thus we determined the reduction of probing depth for the comparison analysis.

Data in Table 2 showed the highest reduction of pocket depth was found in SBA group at day 90, in comparison with day $0(8.10 \pm 2.80) \mathrm{mm}$. The lowest reduction of probing depth was showed by SBA group at day 90 in comparison with day $30(1.10 \pm 0.57) \mathrm{mm}$. The value of probing depth reduction in SBA group was greater than $\mathrm{HA}$, both between day 0 and day 30 or day 90 . However, the probing depth reduction on day 90 in comparison with day 30 on HA group was greater than SBA group. The $U$ Mann-Whitney test showed a significance difference of probing depth reduction on day 30 and day 90 in comparison with day 0 on SBA and HA group ( $p<0.05)$. However, there was no significant probing depth reduction difference between the two groups on day 90 in comparison with day 30 (Table 3).

According to Table 4, the highest mean of relative attachment loss was found in HA group day $0(11.00 \pm 5.61) \mathrm{mm}$. The lowest mean of relative attachment loss was found in SBA group on day 90 $(1.20 \pm 0.42) \mathrm{mm}$. Further analysis was performed using reduction of relative attachment loss data, considering the difference with baseline value.

Table 5 showed that the highest mean of relative attachment loss reduction was found in SBA group on day 90 in comparison with day $0(9.50 \pm 2.92) \mathrm{mm}$. The lowest mean of relative attachment loss reduction was found in SBA group on day 90 in comparison with day 30 (1.10 \pm 0.74$)$ $\mathrm{mm}$. The $U$ Mann-Whitney analysis showed the mean of relative attachment loss reduction in SBA group on day 30 and day 90 in comparison with day 0 was significantly higher than HA group $(p<0.05)$. The mean of relative attachment loss reduction on day 90 in comparison with day 30 on SBA group was lower than on HA group. However, this difference was not statistically significant.

Table 1. Mean and standard deviation (SD) of probing depth according to observation time and treatment groups

\begin{tabular}{cccc}
\hline & & \multicolumn{2}{c}{ Mean \pm SD of probing depth $(\mathrm{mm})$} \\
\cline { 3 - 4 } Time & $\mathrm{n}$ & $\begin{array}{c}\text { Hydroxyapatite } \\
(\mathrm{HA})\end{array}$ & $\begin{array}{c}\text { Sandwich bone } \\
\text { augmentation } \\
(\mathrm{SBA})\end{array}$ \\
\hline Day - 0 & 10 & $6.40 \pm 1.83$ & $8.70 \pm 2.83$ \\
Day - 30 & 10 & $2.50 \pm 1.84$ & $1.70 \pm 0.48$ \\
Day - 90 & 10 & $1.20 \pm 0.78$ & $0.60 \pm 0.51$ \\
\hline
\end{tabular}

Table 2. Mean and standard deviation (SD) of probing depth reduction according to observation time and treatment groups

\begin{tabular}{|c|c|c|c|}
\hline \multirow[b]{2}{*}{ Time } & \multirow[b]{2}{*}{$n$} & \multicolumn{2}{|c|}{$\begin{array}{l}\text { Mean } \pm \text { SD of probing depth reduction } \\
(\mathrm{mm})\end{array}$} \\
\hline & & $\begin{array}{c}\text { Hydroxyapatite } \\
\text { (HA) }\end{array}$ & $\begin{array}{c}\text { Sandwich bone } \\
\text { augmentation } \\
\text { (SBA) }\end{array}$ \\
\hline Day $0-30$ & 10 & $3.90 \pm 1.91$ & $7.00 \pm 2.98$ \\
\hline Day $30-90$ & 10 & $1.30 \pm 1.76$ & $1.10 \pm 0.57$ \\
\hline Day $0-90$ & 10 & $5.20 \pm 1.31$ & $8.10 \pm 2.80$ \\
\hline
\end{tabular}


Table 3. Summary of post hoc U-Mann Whitney test on probing depth reduction

\begin{tabular}{|c|c|c|c|c|c|c|c|}
\hline \multicolumn{2}{|c|}{ Probing depth reduction } & \multicolumn{3}{|c|}{ Hydroxyapatite (HA) } & \multicolumn{3}{|c|}{ Sandwich bone augmentation (SBA) } \\
\hline & & Day $0-30$ & Day $30-90$ & Day 0-90 & Day $0-30$ & Day 30-90 & Day $0-90$ \\
\hline \multirow{3}{*}{$\begin{array}{l}\text { Hydroxyapatite } \\
\text { (HA) }\end{array}$} & Day $0-30$ & & $0.007^{*}$ & 0.123 & $0.035^{*}$ & $0.002^{*}$ & $0.002^{*}$ \\
\hline & Day $30-90$ & & & $0.000^{*}$ & $0.000^{*}$ & 0.796 & $0.000^{*}$ \\
\hline & Day 0-90 & & & & 0.247 & $0.000^{*}$ & $0.023^{*}$ \\
\hline \multirow{3}{*}{$\begin{array}{l}\text { Sandwich Bone } \\
\text { Augmentation (SBA) }\end{array}$} & Day $0-30$ & 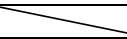 & 7 & & & $0.000^{*}$ & 0.280 \\
\hline & Day $30-90$ & - & & & & & $0.000^{*}$ \\
\hline & Day 0-90 & & & & & & \\
\hline
\end{tabular}

Table 4. Mean and standard deviation (SD) of relative attachment loss according to observation time and treatment groups

\begin{tabular}{|c|c|c|c|}
\hline \multirow[b]{2}{*}{ Time } & \multirow[b]{2}{*}{$n$} & \multicolumn{2}{|c|}{$\begin{array}{l}\text { Mean } \pm \text { SD of relative attachment loss } \\
\qquad(\mathrm{mm})\end{array}$} \\
\hline & & $\begin{array}{l}\text { Hydroxyapatite } \\
\text { (HA) }\end{array}$ & $\begin{array}{c}\text { Sandwich bone } \\
\text { augmentation } \\
(\mathrm{SBA})\end{array}$ \\
\hline Day - 0 & 10 & $11.00 \pm 5.61$ & $10.70 \pm 2.83$ \\
\hline Day - 30 & 10 & $9.60 \pm 5.66$ & $2.30 \pm 0.67$ \\
\hline Day - 90 & 10 & $8.40 \pm 6.29$ & $1.20 \pm 0.42$ \\
\hline
\end{tabular}

Table 5. Mean and standard deviation (SD) of relative attachment loss reduction according to observation time and treatment groups

\begin{tabular}{lccc}
\hline & & \multicolumn{2}{c}{$\begin{array}{c}\text { Mean } \pm \text { SD of relative attachment loss } \\
\text { reduction }(\mathrm{mm})\end{array}$} \\
\cline { 3 - 4 } Time & $\mathrm{n}$ & $\begin{array}{c}\text { Hydroxyapatite } \\
(\mathrm{HA})\end{array}$ & $\begin{array}{c}\text { Sandwich bone } \\
\text { augmentation } \\
(\mathrm{SBA})\end{array}$ \\
\hline Day 0 - 30 & 10 & $1.40 \pm 2.50$ & $8.40 \pm 2.91$ \\
Day 30 -90 & 10 & $1.20 \pm 1.87$ & $1.10 \pm 0.74$ \\
Day 0 0 & 10 & $2.60 \pm 2.12$ & $9.50 \pm 2.92$ \\
\hline
\end{tabular}

Table 7. Mean and standard deviation (SD) of alveolar bone height according to observation time and treatment groups

\begin{tabular}{lccc}
\hline & & \multicolumn{2}{c}{$\begin{array}{c}\text { Mean } \pm \text { SD of alveolar bone } \\
\text { height }(\mathrm{mm})\end{array}$} \\
\cline { 3 - 4 } Time & $\mathrm{n}$ & $\begin{array}{c}\text { Hydroxyapatite } \\
(\mathrm{HA})\end{array}$ & $\begin{array}{c}\text { Sandwich bone } \\
\text { augmentation } \\
\end{array}$ \\
\cline { 3 - 4 } & & $14.15 \pm 4.00$ & $8.32 \pm 2.59$ \\
Day - 0 & 10 & $11.77 \pm 2.22$ & $4.38 \pm 1.90$ \\
Day - 90 & 10 & & \\
\hline
\end{tabular}

Table 8. Mean and standard deviation (SD) of alveolar bone density according to observation time and treatment groups

\begin{tabular}{cccc}
\hline & & \multicolumn{2}{c}{ Mean \pm SD of alveolar bone density } \\
\cline { 3 - 4 } Time & $\mathrm{n}$ & $\begin{array}{c}\text { Hydroxyapatite } \\
(\mathrm{HA})\end{array}$ & $\begin{array}{c}\text { Sandwich bone } \\
\text { augmentation } \\
(\mathrm{SBA})\end{array}$ \\
\hline Day - 0 & 10 & $12.80 \pm 10.96$ & $70.57 \pm 28.75$ \\
Day - 90 & 10 & $40.77 \pm 26.57$ & $93.74 \pm 17.71$ \\
\hline
\end{tabular}

Table 6. Resume of post Hoc U-Mann Whitney test on relative attachment loss reduction among treatment groups

\begin{tabular}{|c|c|c|c|c|c|c|c|}
\hline \multicolumn{2}{|c|}{ Relative attachment loss reduction } & \multicolumn{3}{|c|}{ Hydroxyapatite (HA) } & \multicolumn{3}{|c|}{ Sandwich Bone Augmentation (SBA) } \\
\hline & & Day $0-30$ & Day $30-90$ & Day 0-90 & Day $0-30$ & Day $30-90$ & Day 0-90 \\
\hline \multirow{3}{*}{$\begin{array}{l}\text { Hydroxyapatite } \\
\text { (HA) }\end{array}$} & Day 0-30 & & 0.631 & 0.143 & $0.000^{*}$ & 0.353 & $0.000^{*}$ \\
\hline & Day $30-90$ & & & 0.105 & $0.000^{*}$ & 0.971 & $0.000^{*}$ \\
\hline & Day $0-90$ & & & & $0.000^{*}$ & 0.015 & $0.000^{*}$ \\
\hline \multirow{3}{*}{$\begin{array}{l}\text { Sandwich Bone } \\
\text { Augmentation (SBA) }\end{array}$} & Day 0-30 & & & & & $0.000^{*}$ & 0.280 \\
\hline & Day $30-90$ & 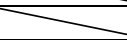 & & & & & $0.000^{*}$ \\
\hline & Day 0-90 & & & & & & \\
\hline
\end{tabular}

As shown on Table 7, the highest mean of alveolar bone height was found in HA group day 0 $(14.15 \pm 4.00) \mathrm{mm}$. The lowest mean of alveolar bone height was found in SBA group on day 90 $(4.38 \pm 1.90) \mathrm{mm}$. The independent t-test was applied on the reduction of bone height on day 90 in comparison with baseline because the data was homogen and normally distributed. The analysis showed no statistically significant difference between HA and SBA group ( $p=0.375)$.

Table 8 demonstrated the highest mean of alveolar bone density was on SBA group on day 90 $(93.74 \pm 17.71) \mathrm{mm}$. The lowest mean of alveolar bone density was found on HA group on day 0 $(12.80 \pm 10.96) \mathrm{mm}$. Bone density reduction on HA group $(27.96 \pm 23.67) \mathrm{mm}$ was higher than SBA 
Majalah Kedokteran Gigi Indonesia. December 2019; 5(3): 114 - 119

ISSN 2460-0164 (print)

ISSN 2442-2576 (online)

group $(23.16 \pm 15.81) \mathrm{mm}$. This difference was not statistically significant $(p=0.348)$.

\section{DISCUSSION}

Probing depth and relative attachment loss on HA and SBA groups decreased by the observation time. This showed an improvement of the clinical parameters on all treatment groups. Bone graft material in the treatment of infrabony pockets stimulates bone formation and periodontal regeneration. Hydroxyapatite material is osteoconductive and able to produce a scaffold for the formation and remodeling of bone, periodontal ligaments, and cementum. ${ }^{2}$ Bone graft material form the structural scaffold for blood clot formation, maturation, remodeling, and formation of bone, cementum and periodontal ligament. ${ }^{9}$

The reduction of probing depth and relative attachment loss on day 30 and day 90, in comparison with day 0 , was significantly different between HA and SBA group. The reduction in SBA group was greater than HA group. Thus, the regeneration process in the SBA group was better than HA group. Both group was treated with open flap debridement and HA but in SBA group, DFDBA was applied to cover the HA layer. DFDBA is osteoconductive material thus able to induce new bone formation and stimulate the maturation of mesenchymal cells. ${ }^{10}$ Histological finding of new attachment in human reveal that DFDBA plays a role in the regeneration of cementum, periodontal ligamen, and bone. ${ }^{11}$

The probing depth and relative attachment loss reduction on day 90 in comparison with day 30 was insignificantly different between HA and SBA group. In this period of time, the periodontal tissue healing process enter the remodeling phase. Fibroblast and endothelial cells experienced apoptosis, leaving the collagen-rich tissue. ${ }^{12}$

The results of the measurement of alveolar bone damage height on day 90 were lower than those on day 0 (baseline) in both groups. The statistical results showed that there was a significant difference between day 0 and day 90 in each group. With a reduction in alveolar bone damage height, bone height increased. The statistical results of the density measurement on day 0 and day 90 in the two treatment groups showed a significant difference. This shows bone repair over time. The radiographic images showed a significant increase in the gray scale value. There is a significant correlation between gray-scale value on cone-beam computed tomography images and bone density. This means that a significant increase in gray-scale value can function as an indicator of a significant increase in bone density. This shows bone repair over time. ${ }^{13}$ Alveolar bone regeneration can be seen from radiographic examination as a radiopaque image around alveolar bone. Regeneration occurs because bone graft material functions to form scaffold for the attachment and proliferation of osteoblast. ${ }^{14}$ Bone graft material will form the structural scaffold for blood clot formation, maturation, remodeling, and formation of bone and stimulate the formation of cementum and periodontal ligament in periodontal treatment. ${ }^{9}$

There were no significant differences in alveolar bone height and density in the two treatment groups because the maturation of bone graft materials in laminar bone requires healing time which varies from 3 to 6 months, depending on several factors such as age, wound healing factor, size of bone damage in the grafting area. ${ }^{14}$ Histological analysis of surgical area with an addition of DFDBA after 6 months showed that there was $18.74 \%$ residual bone graft material. ${ }^{15}$

\section{CONCLUSION}

Based on the results of this study, it can be concluded that the addition of bone graft using SBA method in the treatment of infrabony pockets with open flap debridement results in a greater reduction in probing depth and relative attachment loss, but this brings no difference in alveolar bone height and density compared to open flap debridement with an addition of $\mathrm{HA}$.

\section{REFERENCES}

1. Kesic L, Milasin J, Igic M, Obradovic R. Microbial etiology of periodontal disease mini review. Medicine and Biology. 2018; 15(1): 1-6. 
2. Newman MG, Takei HH, Klokkevold PR, Carranza FA. Carranza's clinical periodontology, $11^{\text {th }}$ ed. St. Louis Missouri: Saunders Elsevier; 2012. 127-139.

3. Bartold PM, Gronthos S, Ivanovski S, Fisher A, Hutmacher DW. Tissue engineered periodontal products. J Periodont Res. 2016; 51(1): 1-15. doi: 10.1111/jre.12275

4. Urban IA, Lozada JL, Wessing B, SuarezLopez del Almo F, Wang HL. Vertical bone grafting and periosteal vertical mattress suture for the fixation of resorbable membranes and stabilization of particulate grafts in horizontal guided bone regeneration to achieve more predictable results: a technical report. Int J Periodontics Restorative Dent. 2016; 36(2): 152-159. doi:10.11607/prd.2627

5. Wang HL, Misch C, Neiva RF. "Sandwich" bone augmentation tehnique: rationale and report of pilot cases. Int J Periodontics Restorative Dent. 2004; 24(3): 233-245.

6. Pellegrini G, Pagni G, Rasperini G. Surgical approaches based on biological objective: GTR versus GBR techniques. Int J Dent. 2013; 521547:1-13. doi: 10.1155/2013/521547

7. Giele H, Cassel O. Plastic and reconstructive surgery. Spesialist handbook in surgery. Oxford; 2008.

8. Groeneveld EH, Burger EH. Bone morphogenetic proteins in human bone regeneration. Eur Journal of Endocrinology. 2000; 142(1): 9-21.

9. Dumitrescu AL. Bone grafts and bone graft substitutes in periodontal therapy. Chemicals in Surgical Periodontal Therapy; 2011. 73-144.
10. Bender SA, Rogalski JB, Mills MP, Arnold RM, Cochran DL, Mellonig JT. Evaluation of demineralized bone matrix paste and putty in periodontal intraosseous defects. J Periodontol. 2005; 76(5): 768-777.

doi: 10.1902/jop.2005.76.5.768

11. Boyan BD, Ranly DM, Schwartz Z. Use of growth factors to modify osteoinductivity of demineralized bone allografts: lessons for tissue engineering of bone. Dent Clin North Am. 2006; 50(2): 217-228. doi: 10.1016/j.cden.2005.11.007

12. Smith PC, Cacares M, Martinez C, Oyazun A, Martinez J. Gingival wound healing: an essential response disturbed by aging. J Dent Res. 2015; 94(3): 395-402. doi: $10.1177 / 0022034514563750$

13. Hallman M, Lundgren S, Seneby L. Histologic analysis of clinical biopsies taken 6 months and 3 years after maxillary sinus floor augmentation with $80 \%$ bovine hydroxyapatite and $20 \%$ autogenous bone mixed with fibrin glue. Clint Implant Dent Relat Res. 2001; 3(2): 87-96.

14. Reynolds MA, Aichelmann, Branch GL. Regeneration of periodontal tissue: bone replacement grafts. Dent Clin North Am. 2010; 54(1): 55-71. doi: 10.1016/j.cden.2009.09.003.

15. Wood RA, Mealey BL. Histologocal comparison id healing following tooth extraction with ridge preservation using mineralized vs demineralized freeze dried bone allograft. J Periodontol. 2012; 83(3): 329-336. doi: 10.1902/jop.2011.110270. 